\title{
Accuracy Assessment of Land Use Land Cover Classification using Google Earth
}

\author{
Abineh Tilahun ${ }^{1, *}$, Bogale Teferie ${ }^{2}$ \\ ${ }^{1}$ Department of Geography and Environmental Studies, Adigrat University, Adigrat, Ethiopia \\ ${ }^{2}$ Department of Geography and Environmental Studies, Dilla University, Adigrat, Ethiopia
}

Email address:

ababineh@gmail.com (A. Tilahun)

\section{To cite this article:}

Abineh Tilahun, Bogale Teferie. Accuracy Assessment of Land Use Land Cover Classification using Google Earth. American Journal of Environmental Protection. Vol. 4, No. 4, 2015, pp. 193-198. doi: 10.11648/j.ajep.20150404.14

\begin{abstract}
This study examines the accuracy assessment of land use land cover classification using Google Earth in the case of Kilite Awulalo, Tigray State, Ethiopia for the year 2014. For this study, Landsat-8 OLI_TIRS image of 2014 was used and analyzed using Arc GIS 10.1. Supervised classification scheme was used to classify the images. Under land use and land cover categories Agriculture land, Settlement land, Grazing land, Forest land, Bush land, Water bodies and Bare/stony land were studied. After classification of land use land cover types, 100 Random Points were generated in Arc GIS and converting random points to KML in order to open in Google Earth. Each random point's value verified from Google Earth for accuracy assessment. Google Earth model was used to measure of how many ground truth pixels are correctly classified. For this study, Free Google Earth which was Build in Date 10/7/2013 was used. The result shows that total (overall) accuracy of land use and land cover for 2014 is $82.00 \%$ and Kappa (K) is $77.02 \%$ which is acceptable in both accuracy total (overall) and Kappa accuracy.
\end{abstract}

Keywords: Accuracy Assessment, Google Earth, Kappa, Land Use Land Cover

\section{Introduction}

The LULC change distribution varies in space and time. This is because physical and social characteristics of communities vary in space and time, so do land-use choices, resulting in a spatial pattern of land-use types (Canute et al, 2015). The study of land use land cover pattern is essential for the selection, planning and implementation of the land use schemes to meet the increasing human needs and welfare. This also provides the information for managing dynamics of land use and meeting the demands of increasing human population (Yadav et al. 2010). Therefore, showing the results of land use land cover in the form of maps and statistical data is very important for concerned bodies like planning, management and utilization of land for different purpose (Roy and Giriraj, 2008).

Land use land cover analysis can be done from processed aerial photographs, Satellite images (Landsat image, Quick bird image) and Google Earth (Dash, 2005). Since remote sensed data from the earth orbit can be obtained repeatedly over the same area, they have been very useful to monitor and analyze LUCC in various regions of the earth and greatly contribute to planning and management of available resources, especially in the developing countries where other kinds of background data are often lacking (Dash, 2005; Fakeye et al, 2015).

After doing of land use land cover classification, the accuracy of special data should be defined. Accuracy assessment or validation is an important step in the processing of remote sensing data which determines the information value of the resulting data to a user (Abubaker et al. 2013).

For doing of accuracy assessment we use

1. Ground verification using Global Position System (Observing the area)

2. Compares of the classified image to an image which is assumed to be correct (such as an aerial photograph, Google Earth Image)

3. Asking questions for concerned bodies those they have previous information

In current, researchers tend to use high spatial resolution data in order to obtain more accurate and precise result. In 
this regard, images with high spatial resolution from Google earth that are free to the public are a good source of imagery including satellite images and air photos. Google earth (http://earth.google.com) provided by Google Inc., is a virtual globe programming that maps the earth by superimposition of high resolution satellite images (Shirkou and Aliakbar, 2013). Since it was released in June 2005, Google Earth has aims to provide viewers with "a more realistic view of the world". Beside Google Earth, map data and positional measurement can be obtained using different methods such as conventional or modern land survey methods, Global positional System (GPS) and remote sensing satellite imagery. Each of these methods is of a known positional accuracy (Nagi et al, 2013).

Google earth high-resolution imagery is important for accuracy assessment by comparing of point by point basis.
A random set of points is generated for the area and then using the Google Earth the value for each point is identified. Therefore, this study was intended to examine the accuracy of Land Use Land Cover Classification using Google Earth in the case of in Kilite Awulalo, Tigray State, Ethiopia

\section{Site Description (Location)}

The study area is located in Tigray region; north part of Ethiopia within the geographical grid coordinates of $13^{\circ} 33^{\prime} 37.618^{\prime \prime} \mathrm{N}$ to $13^{\circ} 57^{\prime} 29.447^{\prime \prime} \mathrm{N}$ latitude and $39^{\circ} 18^{\prime} 8.606^{\prime \prime} \mathrm{E}-39^{\circ} 41^{\prime} 44.647^{\prime \prime} \mathrm{E}$ longitude. The District is bounded with Saesie Tsaedaemba District in the north, Hawzen District in the North West, Enderta District in the south, Degua Temben District in the south west and Atsbi wenberta District in the east.

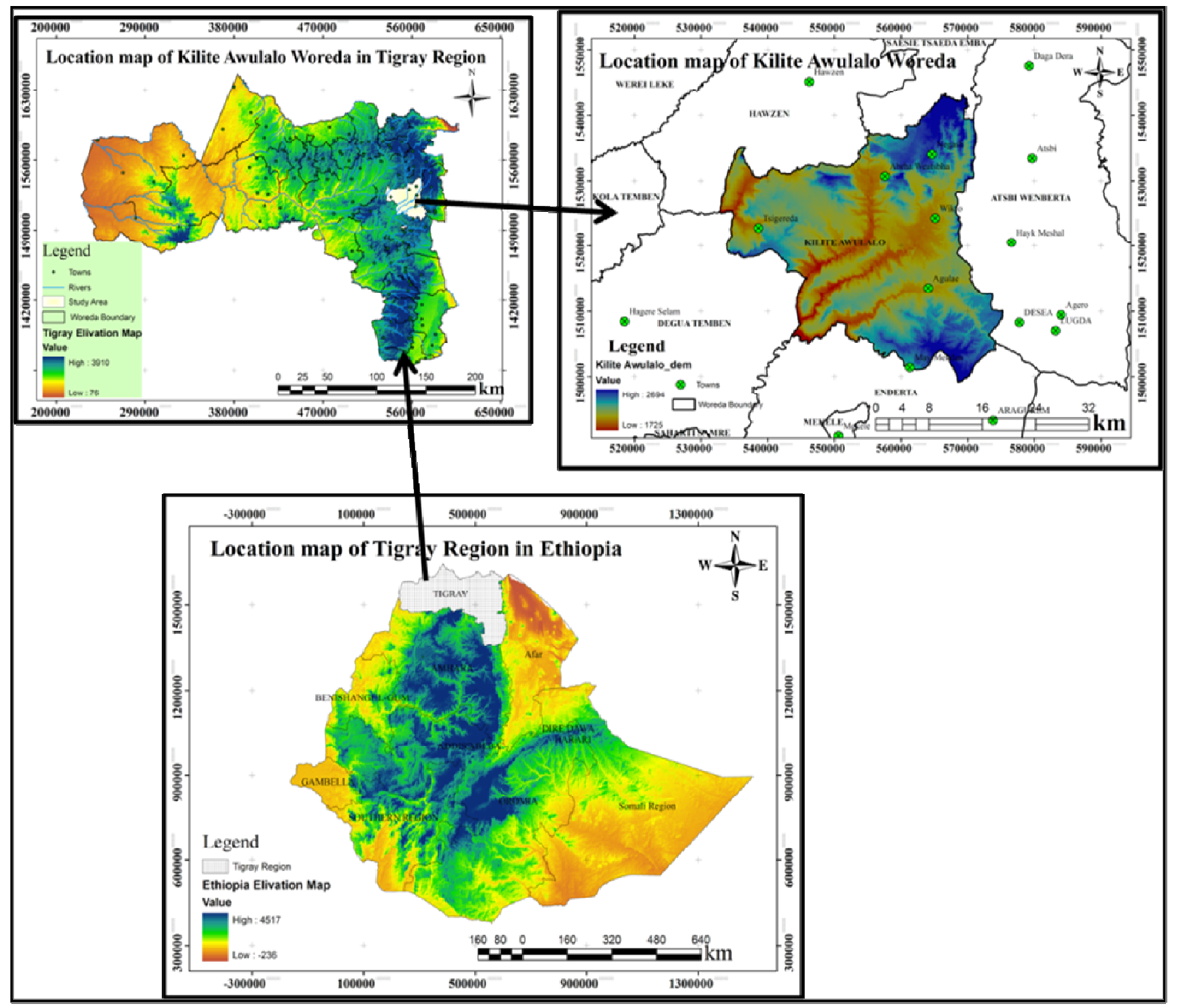

Figure 1. Location map of the study area. 


\section{Materials and Methods}

\subsection{Data Used}

Satellite imagery covering the period 2014 (Landsat-8 OLI_TIRS) were used for land use land cover analysis. The detail of the satellite images is given below.

Table 1. Source and Satellite Images data collection processing.

\begin{tabular}{llllll}
\hline Satellite/ Spacecraft_ID & Sensor ID & Path/row & Date of acquisition & \multicolumn{2}{l}{ Spatial resolution/Grid Cell Size } \\
$(\mathbf{m})$ & Sun Elevation & Cloud Cover \\
\hline \multirow{3}{*}{ Landsat-8 } & & $168 / 50$ & $2014-03-07$ & $30 \mathrm{~m}$ & 0.60 \\
& \multirow{2}{*}{ OLI_TIRS } & $168 / 51$ & $2014-03-23$ & $30 \mathrm{~m}$ & 61.10639256 \\
& & $169 / 50$ & $2014-03-30$ & $30 \mathrm{~m}$ & 62.39484780 \\
\hline
\end{tabular}

\subsection{Software Used}

The following software was used for the processing and/or analysis of data/images.

a) Arc GIS 10.1: Preparation of Location of the project area, Data base generation

b) Erdas Imagine 13: For Image classification

c) Google Earth for creating KML files and verifying of randomly generated points

\subsection{Methods of Data Analysis}

Landsat image 8, Bands 4, 3 and 2 are used to combine to make true-colour composite images for land use land cover analysis and supervised image classification was done. Which means, the analysts trains the computer to recognize patterns in the data by selecting pixels that represents patterns or land cover features that she recognizes, The signature files thus created are then used in the classification process where each pixel is categorized into the land cover class it mostly resembles. After image classification was done, free Google Earth which was Build in Date 5/17/2013 was used for accuracy assessment.

Accuracy assessment was measured though matrix using user classification and reference image Individual accuracy was measured using equation 1

$$
\text { Individual accuracy }=\frac{\text { Reference value }}{\text { row total }}
$$

Overall accuracy was measured using equation 2

$$
\text { Total }\left(\text { overall) accuracy }=\frac{\text { Number of correct plots }(\text { Value })}{\text { Total number of plots }(\text { Value })} \times 100\right.
$$

Kappa can be used as a measure of agreement between model predictions and reality (Congalton 1991) or to determine if the values contained in an error matrix represent a result significantly better than random (Jensen 1996). Kappa was computed using Equation 3.

$$
\mathrm{K}=\frac{N \sum_{i=1}^{r} x_{i i}-\sum_{i=1}^{r}\left(x_{i+} \times x_{+i}\right)}{N^{2}-\sum_{i=1}^{r}\left(x_{i i} \times x_{+i}\right)}
$$

\section{Results and Discussion}

Based on satellite image analysis and observation of the current situation six major land uses and land cover types were identified in the study area. These include Settlement, Agriculture, Forest,
Rocky, Bush Land and Water bodies

\subsection{Land Use Land Cover Classification for 2014}

The land use land cover classification of the area for 2014 from OLI_IRS satellite image (table 2) showed that the majority of the study area is covered by bush land 40573.53 hectares (ha), contributes $40.03 \%$ of the total area. Forest land and agriculture land cover an aerial size of 11916.4 ha $(11.76 \%)$ and 30402.27 ha (30\%) respectively, whereas the aerial coverage of Rocky/Bare and Settlement land is 13974.39 ha $(13.78 \%)$ and 4461.48 ha $(4.41 \%)$ from the total area of the District. There are also artificial waters which covers $1.79 \%$.

Table 2. LU/LC classes, their corresponding areas for 2014.

\begin{tabular}{lll}
\hline \multirow{2}{*}{ LULC Categories } & $\mathbf{2 0 1 4}$ & \\
\cline { 2 - 3 } & Area (Hectare) & Area (\%) \\
\hline Forest & 11916.4 & 11.76 \\
Bush land & 40573.53 & 40.06 \\
Agriculture & 30402.27 & 30.00 \\
Settlement & 4461.48 & 4.41 \\
Rock/Bare & 13974.39 & 13.78 \\
Water Bodies & 18.09 & 1.79 \\
Total & 101346.12 & 100.00 \\
\hline
\end{tabular}




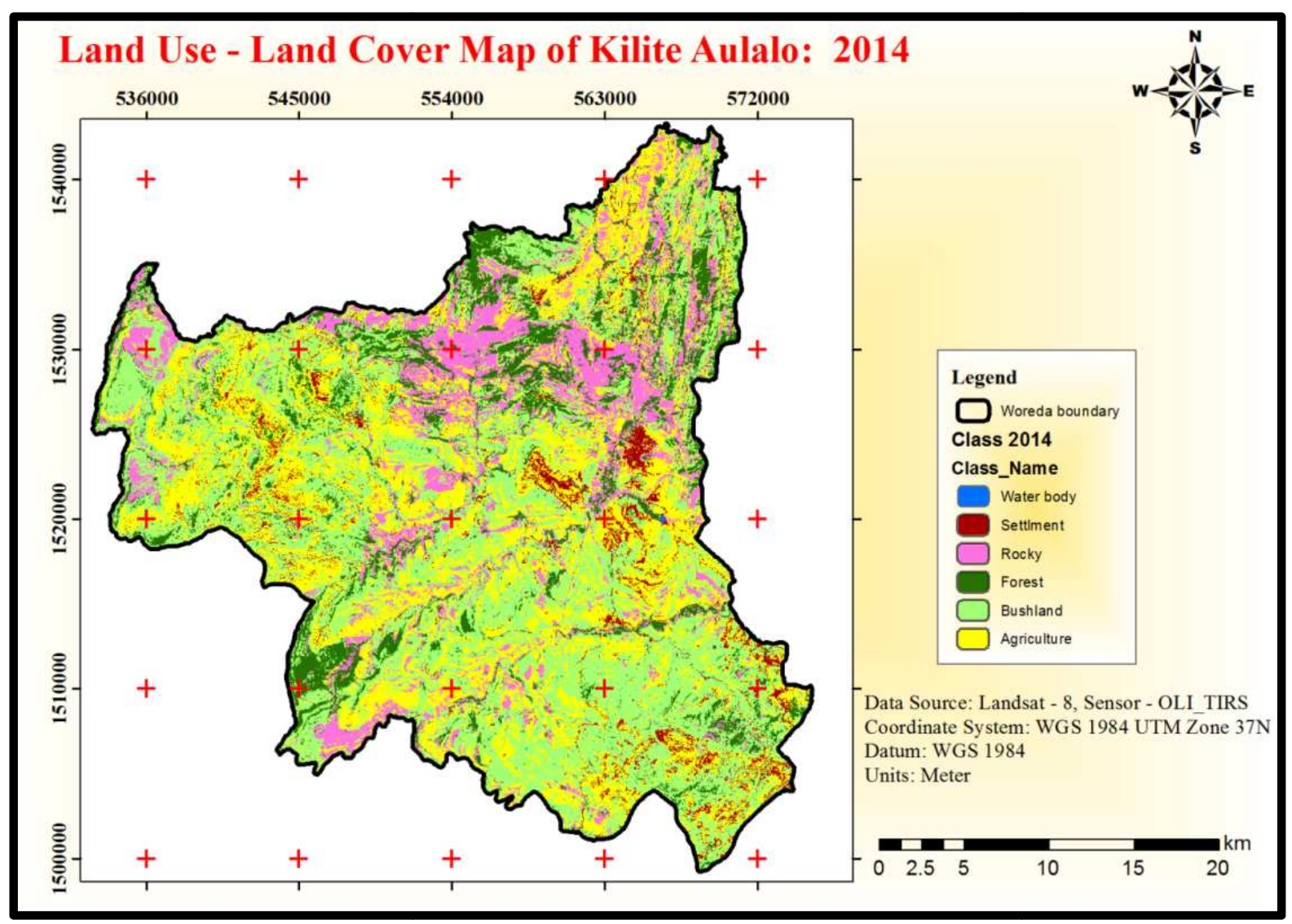

Figure 2. Land use and land cover map of the Kilite Awulalo in 2014.

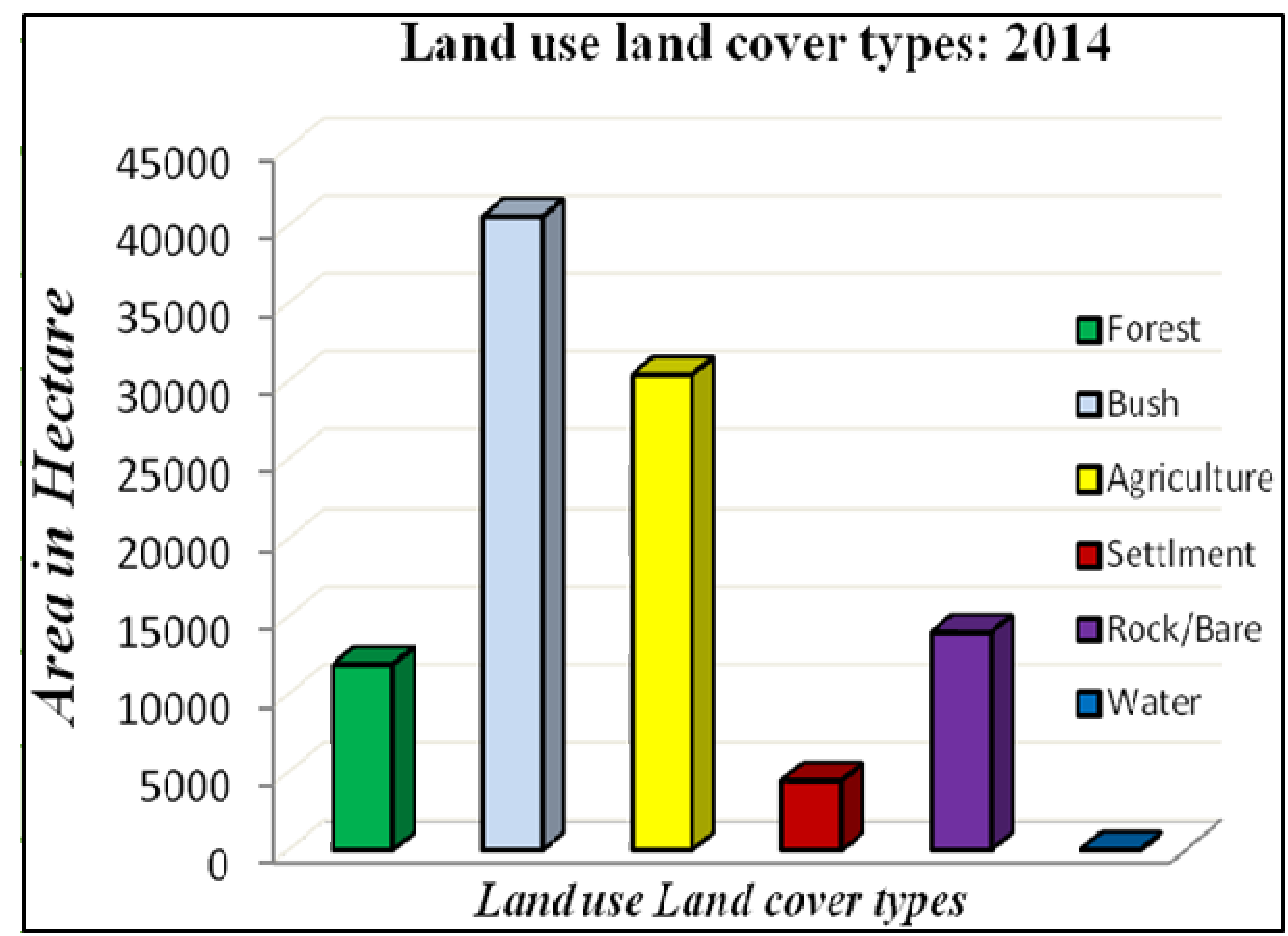

Figure 3. LU/LC classes, their corresponding areas for 2014.

\subsection{Accuracy Assessment of Classifications for 2014}

Google Earth represents a powerful and attractive source of positional data that can be used for investigation and preliminary studies with suitable accuracy and low cost. Since Images from Google Earth with high spatial resolution are free for public and can be used directly in land use land 
cover mapping in small geographical extend. A study which was conducted by Abineh and Zubairul in 2015, and the result of accuracy assessment of land use land cover with the help of Google Earth was more than $75 \%$ which is acceptable.

After image is classified, generating a set of random 100 points was done in ArcMap (Toolbox $>>>$ Data Management Tools $>>$ Feature Class $>>$ Create Random Points $>>>$ create extract values to points. Then the value of each random points were identifying from Google Earth image.

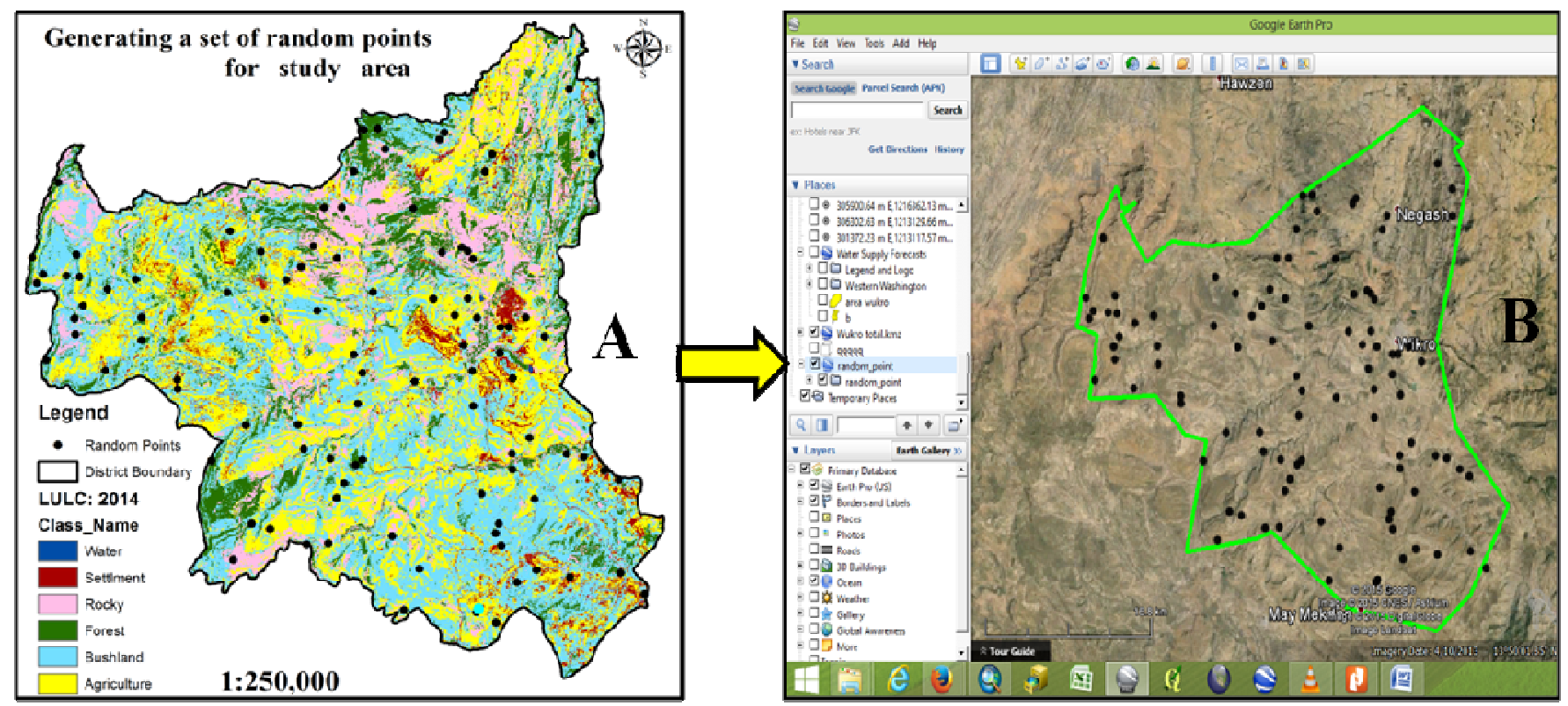

Figure 4. Generating random points in ArcMap (A) and opening the points in Google Earth (B).

Table 3. Accuracy assessment of land use land cover: 2014.

\begin{tabular}{|c|c|c|c|c|c|c|c|c|c|}
\hline & & \multicolumn{8}{|c|}{ Reference from Google earth 2013} \\
\hline & & Settlement (1) & Agriculture (5) & Forest (19) & $\begin{array}{l}\text { Rocky } \\
\text { (27) }\end{array}$ & $\begin{array}{l}\text { Bush } \\
(34)\end{array}$ & $\begin{array}{l}\text { Water } \\
(54)\end{array}$ & Row Total & Ind. ACC \\
\hline \multirow{7}{*}{$\begin{array}{l}\text { User Image } \\
\text { (2014 } \\
\text { Classified) }\end{array}$} & Settlement (1) & 6 & 2 & 0 & 1 & 1 & 0 & 10 & 0.6 \\
\hline & Agriculture (5) & 0 & 21 & 0 & 0 & 3 & 0 & 24 & 0.875 \\
\hline & Forest (19) & 0 & 1 & 16 & 1 & 3 & 0 & 21 & 0.79 \\
\hline & Rocky (27) & 0 & 1 & 0 & 12 & 1 & 0 & 14 & 0.857 \\
\hline & Bush Land (34) & 0 & 2 & 1 & 0 & 24 & 0 & 27 & 0.88 \\
\hline & Water (54) & 0 & 0 & 0 & 0 & 1 & 3 & 4 & 0.75 \\
\hline & Column Total & 6 & 27 & 17 & 14 & 33 & 3 & 100 & 0.792 \\
\hline
\end{tabular}

Total $($ overall $)$ accuracy $=((6+21+16+12+24+3) / 100) * 100=81 / 100=0.85=82.00 \%$

$$
\begin{gathered}
\mathrm{K}=\frac{100(6+21+16+12+24+3)-[(10 \times 6)+(24 \times 27)+(21 \times 17)+(14 \times 14)+(27 \times 33)+(4 \times 3)]}{(100)^{2}-[(10 \times 6)+(24 \times 27)+(21 \times 17)+(14 \times 14)+(27 \times 33)+(4 \times 3)]} \\
\mathrm{K}=\frac{100(82)-[(60)+(648)+(357)+(196)+(891)+(12)]}{10000-[(60)+(648)+(357)+(196)+(891)+(12)]} \\
\mathrm{K}=\frac{8200-2164}{10000-2164}=\frac{6036}{7836}=0.7702
\end{gathered}
$$

So Kappa of 0.7716 means there is $77.02 \%$ better agreement than by chance alone

\section{Conclusion}

Google Earth represents a powerful and attractive source of positional data that can be used for investigation and preliminary studies with suitable accuracy and low cost. So Google Earth is very important for mapping of different types of land use/land cover and for accuracy assessment. The result of accuracy shows that total (overall) accuracy of land use and land cover is $82.00 \%$ and Kappa $(\mathrm{K})$ is $77.02 \%$ which is acceptable in both accuracy total (overall) and Kappa accuracy. 


\section{References}

[1] Abineh Tilahun and I. Zubairul .2015. Use of Google Earth for Land Use mapping in the Case of Gish Abbay Sekela, West Gojjam, Amhara State, Ethiopia. International Journal of Society and Humanities (ISSN-2319-2070/VOL 6:1-6.

[2] Abubaker, H. M, Elhag A.M.H. and Salih, A.M. (2013). Accuracy Assessment of Land Use and Land Cover Classification (LU/LC) Case study of Shomadi area-Renk County-Upper Nile State, South Sudan. International Journal of Scientific and Research Publications, Volume 3, Issue 5.

[3] Canute Hyandye, Christina Geoffrey Mandara, John Safari. GIS and Logit Regression Model Applications in Land Use/Land Cover Change and Distribution in Usangu Catchment. American Journal of Remote Sensing.Vol. 3, No. 1, 2015, pp. 6-16. doi: 10.11648/j.ajrs.20150301.12.

[4] Congalton, R. G. 1991. A review of assessing the accuracy of classifications of remotely sensed data. Remote Sensing of Environment 37:35-46.

[5] Dash, P. (2005). Land Surface Temperature and Emissivity Retrieval from Satellite Measurements, Institut fur Meteorologie und Klimaforshung.

[6] David, P. (2008). Horizontal Positional Accuracy of Google Earth's High Resolution Imagery Archive. Sensors 2008, 8, 7973-7981; DOI: 10.3390/s8127973.

[7] Fakeye, Attah Motunrayo, Aitsebaomo, Francis Omokekhai, Osadebe, Charles Chuka, Lamidi, Risikat Bukola, Okonufua, Endurance Omamoke. Digital Modeling of Land Use Changes in Some Parts of Eastern Nigeria. American Journal of Remote Sensing. Vol. 3, No. 3, 2015, pp. 37-42. doi: 10.11648/j.ajrs.20150303.11

[8] Jensen, J. R. 1996. Introductory Digital Image Processing: A Remote Sensing Perspective (Second edition). Prentice Hall, Inc., Upper Saddle River, New Jersey, USA.

[9] Nagi, Z. M, Ahmed G. and Hussam E. (2013). Positional Accuracy Testing of Google Earth. International Journal Of Multidisciplinary Sciences And Engineering, VOL. 4, NO. 6, JULY 2013

[10] Roy, P.S. and Giriraj, A. 2008. Land Use and Land Cover Analysis in Indian Context. Journal of applied science, Vol. 8(8): 1346-1353.

[11] Shirkou, J. and Aliakbar, N. (2013). Comparison between Land Use/Land Cover Mapping Through Landsat and Google Earth Imagery. American-Eurasian J. Agric. \& Environ. Sci., 13 (6): $763-768$.

[12] Yadav, P., Kapoor, M. and Sarma, K. 2010. Land Use Land Cover Mapping, Change detection and conflict Analysis of Nagzira-Navegaon Corridor, Central India Using Geospatial Technology. International Journal of Remote Sensing and GIS, Vol. 1(2): 90-98. 